Stephan Winter and Nicole C. Krämer

\title{
A question of credibility - Effects of source cues and recommendations on information selection on news sites and blogs
}

\begin{abstract}
Internet users have access to a multitude of science-related information - on journalistic news sites but also on blogs with user-generated content. In this context, we investigated in two studies the factors which influence laypersons' selective exposure $(N=101)$. In an experiment with a collection of online news, parents were asked to search for information about the controversy surrounding violence in the media. Texts from high-reputation sources were clicked on more frequently - regardless of content -, whereas ratings by others had limited effects. In a second experiment, the expertise and gender of blog authors as well as valence and number of ratings were varied. In this setting, texts from sources with positive ratings were read for longer. Results show that laypersons make use of credibility cues when deciding which articles to read. For online news sites, media reputation is most important, whereas in blogs, ratings are taken into account more frequently.
\end{abstract}

Keywords: selective exposure, source credibility, online news sites, Web 2.0

DOI 10.1515/commun-2014-0020

\section{Introduction}

Due to the development of the internet, access to information has become easier than ever before. The available content in the World Wide Web may consist of articles produced by professional journalists on online news sites but also of user-generated content in Web 2.0 applications such as blogs or Wikipedia. For readers who are interested in a specific topic, both journalistic sources and websites with user-generated content offer valuable opportunities to acquire

Stephan Winter, Dr. phil., is research associate at the University Duisburg-Essen, Germany, E-mail: stephan.winter@uni-due.de

Nicole C. Krämer, Dr. phil., is Professor for Social Psychology at the University DuisburgEssen, Germany, E-mail: nicole.kraemer@uni-due.de 
relevant information; however, the abundance of documents with potentially huge differences in information quality might also lead to the problem of users becoming lost owing to this quantity of content. This situation may be particularly challenging in the domain of scientific topics: Here, the web offers unprecedented sources of information on science-related questions ("Should I be vaccinated?" or "Should my child be allowed to play video games?"), however, most topics are too complex to be understood deeply by non-experts (Bromme, Kienhues, and Porsch, 2010).

Against this background, this work aims to investigate the factors which influence laypersons' selection of online science information. Due to the diversity of sources that publish online information - ranging from journalists of quality newspapers to the less reputable tabloid press, and from knowledgeable bloggers to potentially unreliable laypersons - the question arises of whether readers include reasoning about the credibility of the given sources when deciding which articles to read and which not. Therefore, we focus on the effects of source cues (as a traditional marker of credibility) and evaluations by other users in terms of community ratings (which can also be used to infer the credibility and quality of the given sources and their information (Metzger, Flanagin, and Medders, 2010).

Although sources and their credibility appear to be increasingly relevant in the online context (Westerwick, Kleinman, and Knobloch-Westerwick, 2013), prior research on selective exposure and information seeking has not concentrated on this factor and mainly focused on the attitude-consistency (e.g., Knobloch-Westerwick and Meng, 2009) or the utility and relevance of content (e.g., Pirolli and Card, 1999). Therefore, one goal of this work is to extend research on selective exposure with regard to credibility perceptions of the given sources. Moreover, we aim to compare the processes of information selection on an online news collection site offering information taken from journalistic sources and on a blog platform in a Web 2.0 setting.

In this article, we will discuss the concept of credibility with respect to the heterogeneity of online sources and its connection to information selection on the web. In particular, we will deal with the potential effects of source cues as well as of evaluations by other readers. Following this, the results of two experimental studies in which we analyzed users' information selection regarding a science-related debate as well as perspectives for further research will be presented.

\subsection{Credibility and information selection}

Credibility is a multifaceted construct that is relevant on different levels (Metzger, Flanagin, Eyal, Lemus, and McCann, 2003): It can refer to a whole medium, 
a source within a medium, or single messages (Sundar and Nass, 2001). As Tseng and Fogg (1999) pointed out, credibility is not an objective characteristic of a source or a message, but rather the result of an attribution process by the recipient.

Classic considerations of source credibility and its (at least) two dimensions, competence and trustworthiness, date back to the Yale studies by Hovland and colleagues (Hovland, Janis, and Kelley, 1953). The dimension of competence relates to the perception whether a source is able to provide valid statements on a topic, while trustworthiness refers to the perception whether a source is willing to communicate the correct information. In their early studies, Hovland and colleagues showed that a message which was attached to a credible source (an expert or a reputable journal) was more influential than the same message in association with a less credible source (layperson or a tabloid paper). With regard to the internet, previous research has mainly investigated the general credibility of the web as a medium or the credibility of different websites (cf. Metzger et al., 2003). However, due to the development of news aggregators such as Google News or Digg and Web 2.0 applications, the question of credibility on the web is no longer limited to site credibility (Kang, Bae, Zhang, and Sundar, 2011). Instead, we argue that it has to be extended to the single sources within these sites, that is, journalistic sources which are listed in news aggregators, and online users who produce content in communities for user-generated content.

With the huge amount of information available, the internet particularly promotes selective exposure (Westerwick et al., 2013). Since credibility can be seen as one important criterion for deciding whether to use or reject information (Metzger et al., 2003; Wathen and Burkell, 2002), it seems plausible to connect the construct of preliminary credibility evaluations (e.g., when reading headlines and source descriptions) with the process of information selection: Information which is seen as incorrect or inappropriate by the user will not be chosen for further reading. Thus, information regarding source and message credibility will be relevant not only in persuasion processes, but also at an earlier stage, when deciding which article to choose for further reading. Therefore, we propose that the attribution of credibility is a prerequisite for the selection of information and source descriptions should be included as one further factor influencing selective exposure.

The fact that for a specific topic, articles from different sources are easily available and within clicking distance on the web renders the situation different from the traditional usage of print media (when recipients typically just read one newspaper). This may be one reason why aspects of credibility have not been considered extensively in traditional selective exposure research. Only 
for the pre-communicative phase, when deciding which newspaper to buy, was the reputation (or the political orientation) of a source taken into account (Donsbach, 1991). Due to the increased user control over the selection process (Westerwick et al., 2013) and the large amount of content which may foster selective scanning between different pieces of information (Eveland and Dunwoody, 2002), it is to be expected that the importance of the credibility of a source is greater in the context of online information.

In the following, we will discuss the potential influence of cues regarding the reputation and expertise of message sources, and their evaluations by other users on readers' selection behavior, since these social psychological aspects are most likely to convey valuable hints as to the quality to be expected of the articles that can be chosen for further reading. What remains open is the question of how multiple cues with potentially contradictory information (as found in participatory web environments) operate, whether and how they interact, and which information is strongest in determining users' impressions and selection behavior.

\subsection{The influence of source cues}

The characteristics of a source are decisive when estimating credibility. As mentioned above, research has largely shown that messages which are presented by sources that are seen as competent and trustworthy are more successful in influencing readers' attitudes (e.g., Pornpitakpan, 2004). On news aggregators, the name of the original medium (e.g., New York Times) - which is connected to a specific reputation and expectation among readers - provides the most relevant source information. Such information is likely to trigger the authority heuristic (Sundar, 2008), which is based on the belief that reputable sources are usually correct. Applying this reasoning to the selection of information, Sundar, Knobloch-Westerwick, and Hastall (2007) found that participants tended to report a greater likelihood of clicking (assessed via questionnaire) when the article was attached to a reputable source.

For the setting of user-generated content with blog authors, a more complex pattern of credibility evaluation is possible: Laypersons are likely to be perceived as less competent than experts but they may have an advantage in perceived trustworthiness (since they are similar to most readers and usually have no persuasive intent). For online product reviews, Willemsen, Neijens, and Bronner (2012) found that experts (indicated by self-claims in the text) were seen as more competent but less trustworthy than layperson reviewers - only rated experts (indicated by a "top reviewer" badge) led to high level evaluations 
in both dimensions of credibility. In the context of science information, Winter and Krämer (2012) showed positive effects of expertise in author descriptions on selective exposure, which may imply that the sub-dimension of perceived competence is most important for selection decisions. However, although this application of the expertise heuristic appears to be a reasonable strategy, there are still reasons to doubt whether author information in Web 2.0 is always correct: For instance, people may claim that they are experts although they are not.

\subsection{The influence of recommendations}

Due to the interactive nature of the web, users have the possibility to express their opinions on any topic and rate and recommend online content. These user-generated ratings or popularity indications probably produce a bandwagon effect (Chaiken, 1987; Sundar, 2008) if they are based on a considerable number of votes (probably in comparison to the standards of the specific platform). Accordingly, previous research, particularly in the context of e-commerce, has shown a significant relationship between ratings or reviews and consumer intentions (Chevalier and Mayzlin, 2006).

For the context of online articles, Knobloch-Westerwick, Sharma, Hansen, and Alter (2005) found positive effects for explicit recommendations (in the form of ratings) on participants' reading time. For implicit recommendations ('times viewed'), there was a curvilinear effect, with longer reading times for articles with very low (around 50) and very high (more than 200) numbers of views. While the former suggests that articles with few clicks appear to be recent, the latter can be interpreted in the sense of the bandwagon effect. However, a study with authors on science blogs (Winter, Krämer, Appel, and Schielke, 2010) did not show main effects of community ratings. Although ratings generated by others are difficult to manipulate by the source and therefore should be perceived as valuable information, credibility perceptions and selection decisions were more strongly influenced by author expertise. This may indicate that a science setting leads to traditional expertise cues being more important. The experimental webpage did, however, not include further information on the community or the number of ratings, meaning that the influence of ratings may be stronger in environments with an obviously active and reliable community.

While both - the authority heuristic as well as the bandwagon heuristic (Sundar, 2008) - appear to be reasonable at first glance, little is known about the relative importance of these heuristics in comparison with each other. 
Therefore, one goal of this work is to investigate whether source or bandwagon cues are more important for credibility perceptions and selective exposure and what happens if the cues are inconsistent. Study 1 investigates these aspects in the setting of online news collections (with sources of high and low reputation, with positive or negative ratings, and high or low numbers of views), whereas Study 2 employs a Web 2.0 setting: Here, the expertise and gender of blog authors and ratings are the corresponding factors.

\section{Study 1}

\subsection{Overview and hypotheses}

The purpose of the first study was to investigate the influence of source cues and recommendations when readers select information in news aggregators (such as Google News) or social news applications (such as Digg or Reddit). Based on the theoretical background reported above, we expected users to prefer articles from reputable sources which are likely to trigger the authority heuristic (Metzger et al., 2010; Sundar, 2008).

[H1] Texts from sources with a high reputation are evaluated as more credible, selected more often for further reading, read for longer and selected earlier than texts from sources with a low reputation.

Apart from the source, user-generated statements may also convey information about the credibility and quality of articles. Here, content ratings as well as popularity indications are capable of triggering bandwagon perceptions (Chaiken, 1987; Sundar, 2008).

[H2] Texts with a positive rating are evaluated as more credible, selected more often for further reading, read for longer and selected earlier than texts with a negative rating.

[H3] Texts with a high number of views are evaluated as more credible, selected more often for further reading, read for longer and selected earlier than texts with a low number of views.

As a further exploratory research question, we tested whether authority or bandwagon perceptions are influenced by characteristics of the users: Since need for cognition (NC) - the tendency to enjoy and engage in effortful think- 
ing - has been shown to influence the level of elaboration (Cacioppo and Petty, 1982), we asked whether people with higher NC engage in more thoughtful selection decisions based on credibility evaluations than people with lower NC.

In order to investigate these issues, we created an experimental webpage which includes the relevant factors: a collection of online news with articles from different sources dealing with the exemplary topic of the science-related debate on violence in the media.

\subsection{Method}

Sample. The sample of the study consisted of 61 participants (32 female, 29 male) between the ages of 28 and 49 years $(M=40.72$; $S D=4.55)$. Participants were parents (of minors). This group was chosen since the topic of the stimulus material (violence in the media and its effects on children) is likely to be personally relevant to parents. In order to recruit parents, newspaper ads and press releases were published, and flyers were distributed in schools. Respondents received 25 Euros for taking part in the experiment.

Design and stimulus material. The experimental website with the title "News Collection", including relevant aspects of news aggregators and social news sites, served as stimulus material. On the overview page, eight articles were shown (with a headline and short summary). The website was programmed using an HTML editor, and the design was kept similar to existing websites (see Figure 1).

As independent variables, the reputation of the source, the community ratings, and the number of views were systematically varied. In other words, the reputation of the online medium which was shown as the source was either high or low (websites of quality newspapers and magazines vs. websites of tabloid press or smaller regional newspapers). Based on the results of an online pretest with an additional 33 participants (22 female; age: $M=27.61 ; S D=7.98$ ), we selected four sites which were rated as high-quality journalism (with similar values) and four sites which were evaluated less positively. The difference between these groups with regard to quality ratings was significant, $F(1,32)=$ 151.63, $p<.001, \eta_{p}{ }^{2}=.83$. Community ratings were either positive (four or five out of five stars) or negative (one or two out of five stars), and the number of views was either high (approximately 400 clicks) or low (approximately 40 clicks, similar to the numbers used by Knobloch-Westerwick et al., 2005). On the overview page of the website, all eight source combinations were shown $(2 \times 2 \times 2$ within-subjects design).

Headlines (four to eight words) and summaries (one to two sentences) were written in a neutral tone (e.g., "New studies on the effects of first-person shoot- 


\section{News Collection}

Aktuelle Umfrage in deutschen Schulen ausgewertet sueddeutsche de - 59 -mal gelesen

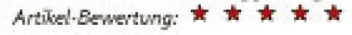

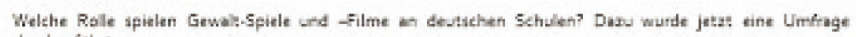
durchgefihrt

wimehr]

Neue Studien zu den Wirkungen von Ego-Shootern veröffentlicht SODKURIER - 412 -mal gelesen Artikel-Eewertung: t t t t t t

Neut Studien zum Thems _Wrrungen won Ego-Shootem wurden jetzt veroffenticht. Dabes wurde der

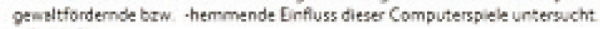
wimehr]

Umfrage zum Fernsehwerhalten der Kinder (IF) : 29 mal gelesen

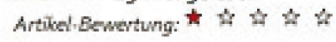

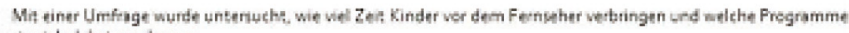
sesich dobei anghsuen c..Imehr]

Aktuelle Umfrage in lugendvereinen ausgewertet

MAINVa POST - 44-mal gelesen

Artikel-Bewertung: औ औ

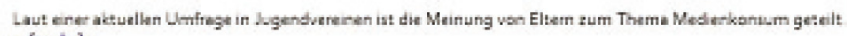
wimehr]

Kürzungven Kinofilmen - Pround Contra

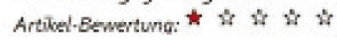

Figure 1: Stimulus material of Study 1: Overview page of the news collection website.

ers") and did not indicate a for or against position with regard to the controversial issue (in order to avoid an effect of attitude-consistent selective exposure; see Knobloch-Westerwick and Meng, 2009). Furthermore, connections between authors and texts were systematically rotated to control for effects of the different topics. The length of the complete articles ranged from 89 to 109 words.

Moderating variables. Besides age and education, we assessed users' need for cognition (Bless, Wänke, Bohner, Fellhauer, and Schwarz, 1994; Cacioppo and Petty, 1982) with 16 items (Cronbach's $\alpha=.84 ; M=58.62 ; S D=8.85$ ).

Dependent measures. As dependent measures, credibility ratings and information selection were assessed. We coded which of the texts from which sour- 
ces were chosen (in which order) and for how long the texts were read. After using the webpage, participants evaluated the credibility of the given sources with six adjective pairs on semantic differentials (Gierl, Stich, and Strohmayr, 1997) which showed high levels of reliability (Cronbach's $\alpha$ between .89 and .95) and were thus added to form a unidimensional credibility score. Since three items referred to perceived competence ("competent - incompetent", "experienced - not experienced", "qualified - non-qualified") and three to perceived trustworthiness ("trustworthy - untrustworthy", "honest - dishonest", "unselfish - selfish"), we additionally calculated sub-scores for both dimensions of credibility (Cronbach's $\alpha$ between .73 and .96).

Procedure. The study was conducted in a laboratory room of a large European university. After filling out the online questionnaire on the moderating variables and surfing on a further website, participants were asked to look the "news collection" page, inform themselves about the topic and choose what they found worthwhile reading (similar to instructions by Knobloch-Westerwick and Meng, 2009). In order to create a selection situation, reading time was limited to three minutes. The sessions were unobtrusively saved through screen-recording software.

\subsection{Results}

During three minutes of browsing time, participants selected an average of 4.02 articles $(S D=1.38)$ for further reading. As statistical tests of the hypotheses, we conducted analyses of variance (ANOVA) with repeated measures and source reputation, community rating, and number of views as independent variables.

For the dependent measure of credibility perceptions, ANOVA showed significant effects of source reputation, $F(1,60)=139.82, p<.001, \eta_{p}{ }^{2}=.70$, as well as of community ratings, $F(1,60)=10.21, p=.002, \eta_{p}{ }^{2}=.15$. According to the mean values (see Table 1), participants perceived reputable sources as well as sources with a positive rating as more credible. A significant disordinal interaction between rating and number of views, $F(1,60)=45.17, p<.001$, $\eta_{p}{ }^{2}=.43$, indicated that the effect of positive ratings was particularly relevant in combination with a high number of views, whereas the difference between positive and negative ratings was small (and slightly in the opposite direction) when the number of views was low. A further three-way interaction between all three cues - reputation, rating, and number of views $-F(1,60)=33.16$, $p<.001, \eta_{p}{ }^{2}=.36$, showed the following pattern: The group of high-reputation sources was most credible (with the peak value when ratings and views were also high), while the credibility of low-reputation sources depended more 
Table 1: Descriptive statistics - Effects of source reputation, community rating, and number of views on perceptions of credibility.

\begin{tabular}{|c|c|c|c|c|}
\hline Variable & & & $M$ & $S E$ \\
\hline \multicolumn{5}{|l|}{ Reputation } \\
\hline Low & & & 17.18 & 0.46 \\
\hline High & & & 22.86 & 0.41 \\
\hline \multicolumn{5}{|l|}{ Rating } \\
\hline Negative & & & 19.34 & 0.44 \\
\hline Positive & & & 20.70 & 0.40 \\
\hline Rating & Views & & & \\
\hline \multirow[t]{2}{*}{ Negative } & Low & & 20.41 & 0.51 \\
\hline & High & & 18.27 & 0.49 \\
\hline \multirow[t]{2}{*}{ Positive } & Low & & 19.34 & 0.52 \\
\hline & High & & 22.01 & 0.43 \\
\hline \multirow[t]{2}{*}{ Reputation } & Rating & Views & & \\
\hline & Negative & Low & 18.56 & 0.49 \\
\hline \multirow[t]{4}{*}{ Low } & & High & 14.18 & 0.62 \\
\hline & Positive & Low & 16.00 & 0.77 \\
\hline & & High & 20.00 & 0.55 \\
\hline & Negative & Low & 22.26 & 0.68 \\
\hline \multirow[t]{3}{*}{ High } & & High & 22.36 & 0.60 \\
\hline & Positive & Low & 22.67 & 0.51 \\
\hline & & High & 24.13 & 0.48 \\
\hline
\end{tabular}

strongly on the other two cues (see Table 1). Separate analyses for the subscores of perceived competence and perceived trustworthiness showed the same effects.

With regard to the dependent measure of frequency of selection (number of clicks), a significant effect of source reputation emerged, $F(1,60)=16.12$, $p<.001, \eta_{p}{ }^{2}=.21$. The mean values showed that articles connected to a highreputation source $(M=0.60 ; S E=0.03)$ were chosen more frequently than articles connected to low-reputation sources $(M=0.41 ; S E=0.04)$. However, there were no such effects of community ratings and number of views.

A similar pattern emerged for the dependent measure of reading time: Here, ANOVA revealed a significant effect of source reputation, $F(1,60)=24.24, p<$ $.001, \eta_{p}{ }^{2}=.29$, with longer exposure for articles from reputable sources $(M=$ 19.39; $S E=0.98)$ than for low-reputation sources $(M=10.55 ; S E=0.92)$.

The order of selection was also affected by a significant effect of source reputation, $F(1,60)=25.50, p<.001, \eta_{p}{ }^{2}=.30$, with earlier selection of highreputation sources $(M=4.67 ; S E=0.15$ / low-reputation: $M=6.05 ; S E=0.16)$, 
as well as by a significant ordinal interaction of reputation and community rating, $F(1,60)=4.72, p=.034, \eta_{p}{ }^{2}=.07$. In the group of low-reputation sources, participants selected those with a positive rating earlier (positive rating: $M=5.84 ; S E=0.22$ / negative: $M=6.26$; $S E=0.22$ ), whereas the opposite pattern emerged in the group of high-reputation sources (positive rating: $M=$ 4.98; $S E=0.26$ / negative rating: $M=4.36 ; S E=0.18)$.

To investigate the influence of user characteristics (as potential moderators) and perceived credibility (as mediating variable) on the selection behavior, we used regression techniques for testing effects of concomitant variables in within-subject designs (Judd, Kenny, and McClelland, 2001). For this purpose, scores were calculated for the individual preference for high-reputation sources (number of selected texts from high-reputation sources minus selected texts from low-reputation sources) as well as for the preferences for texts with positive ratings (minus negative ratings). These scores were regressed on age, education (dummy-coded: university entrance-level vs. lower qualification), and need for cognition. To test whether credibility perceptions are the underlying reason for readers' selection decisions, difference scores between the perceived credibility of high vs. low reputation sources as well as of sources with positive vs. negative rating were included as further predictors.

For the difference score between high-reputation and low-reputation sources, the difference in perceived credibility emerged as a marginally significant factor, $\beta=.230, p=.076, R^{2}=.159$, indicating that users who evaluated highreputation sources as more credible tended to select them more frequently than users who perceived smaller differences in credibility (the other predictors were not significant). Similarly, for the individual consideration of ratings, the perceived credibility difference between sources with positive and negative ratings emerged as significant predictor of the preference for positively vs. negatively rated sources, $\beta=.375, p=.003, R^{2}=.167$. According to Judd et al. (2001), this suggests that credibility can be interpreted as a mediating variable which (partly) explains differences in selection behavior.

In summary, source reputation appeared as an influential cue when readers search for information from journalistic sources: Texts which were connected to websites of reputable quality newspapers and magazines were evaluated more positively, selected more frequently, read for longer, and selected earlier than their low-reputation counterparts (supporting H1). The influence of source reputation was stronger than the influence of ratings and number of views. Positive ratings were only relevant (in combination with a high number of views) for the perceptions of credibility, and among the texts from low-reputation sources those with a positive rating were selected earlier. Thus, H2, which focused on the effect of ratings, was partially supported. H3, which predicted 
positive effects of a high number of views, was not supported. Results of mediation analyses indicate that the individual preferences for sources are mostly due to different credibility perceptions.

\section{Study 2}

\subsection{Overview and hypotheses}

The second study investigated the factors of source cues and recommendations in a Web 2.0 environment. In this context, the relevant message sources are no longer professional journalists but persons who produce user-generated content, which may lead to differences in the relative importance of authority and bandwagon cues.

With regard to traditional expertise information, the contributors of Web 2.0 sites such as blog authors can be characterized through short self-descriptions, for example, on their profession or their connection to the topic. Despite the potential advantages of laypersons with regard to trustworthiness, the authority heuristic (Sundar, 2008) suggests that experts should have a positive influence on credibility perceptions and information selection in the context of online science information (Winter and Krämer, 2012).

[H4] Authors with a high level of self-reported expertise are evaluated as more credible and their texts are selected more often for further reading, read for longer and selected earlier than texts of authors with a low level of self-reported expertise.

Although Study 1 only showed limited effects of community ratings, we expected that they might produce effects in a Web 2.0 setting since readers often have no experience with the specific blog authors (in comparison to journalistic sources, which are usually well-known) and should therefore pay attention to others' opinions (Chaiken, 1987).

[H5] Authors with a positive community rating are evaluated as more credible and their texts are selected more often for further reading, read for longer and selected earlier than texts of authors with a negative community rating.

However, the mixed results obtained so far may indicate that readers do not trust every community rating but also engage in credibility assessments with 
regard to the community. One relevant factor could be the number of people who contributed to a specific rating since a rating which only consists of a few unknown people's opinions is not very helpful (Lee and Jang, 2010). Furthermore, a community which is known to the user and whose members appear to be reliable may also be a prerequisite for the effect of others' recommendations.

[H6] Community ratings particularly influence users' selection decisions if ratings are given by a high number of users and if the community appears to consist of competent members.

Since the relevant message sources in blogs are people, one may also ask how basic personal information affects users' credibility perceptions and information selection. In an experiment with personal webpages, Flanagin and Metzger (2003) found that participants evaluated opposite-sex authors as more credible. However, with regard to protagonists of texts, Knobloch-Westerwick and Hastall (2006) showed that recipients spend more reading time on news articles with protagonists of the same gender.

[RQ1] What is the effect of the author's gender on the perception of credibility and readers' selection decisions?

To investigate these issues, we conducted a study with an experimental blog platform on the topic of violence in the media. The design and the variables were kept similar to the manipulations of Study 1 but adapted to the specific elements of Web 2.0.

\subsection{Method}

Sample. Participants were 40 parents (21 female, 19 male) aged between 23 and 54 years $(M=39.72 ; S D=6.80)$. Respondents received 25 Euros for their participation.

Design and stimulus material. As stimulus material, we created a webpage in the style of typical blog platforms presenting texts by different authors (see Figure 2). On the overview page, 16 summaries of articles (with a headline and information on the author) were shown. As independent variables, the factors of the author descriptions (gender, self-reported expertise, valence of community ratings, numbers of community ratings) were systematically varied as withinsubject variables $(2 \times 2 \times 2)$. Self-reported expertise was operationalized via profession (professions with a close connection to the topic, e.g., psychologist, vs. 


\section{Gewalt in den Medien}

Neue Studien zu den Wirkungen von Ego-Shootern veröffentlicht Gepostet von Dipl.-Päd. Simon Brahm, Sozialpädagoge Autoren-Bewertung: $\star \star \star \star \star$ (3 Bewertungen)

Neue Studien zum Thema "Wirkungen von Ego-Shootern" wurden jetzt veröffentlicht. Dabei wurde der gewaltfördernde bzw. -hemmende Einfluss dieser Computerspiele untersucht. ...[mehr]

\section{Computerspiele im Kindesalter - Nutzen und Gefahren Gepostet von Prof. Beate Jansen, Medienrechtlerin Autoren-Bewertung: $\star \star \star \star \star \star$ (117 Bewertungen)}

Welchen möglichen Nutzen und welche Gefahren gibt es, wenn bereits Kinder am Computer spielen? ....[mehr]
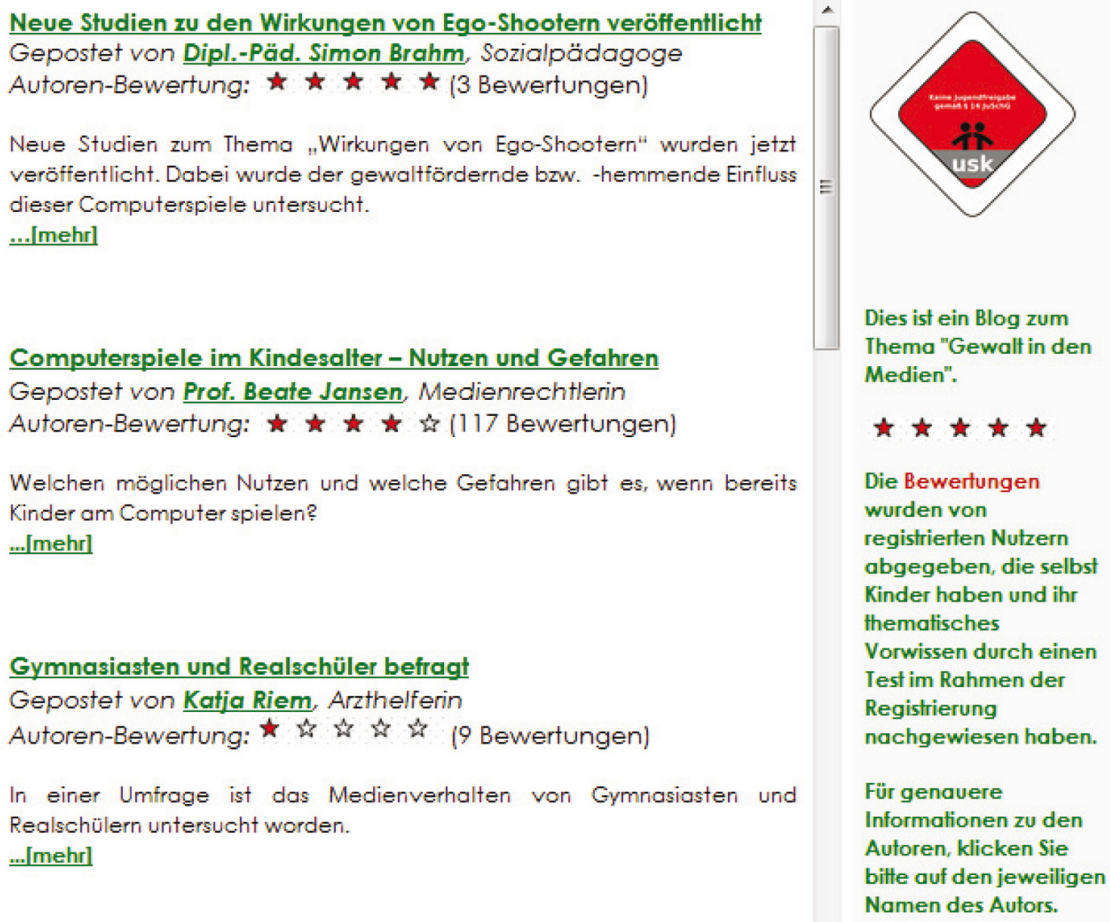

Figure 2: Stimulus material of Study 2: Overview page of the blog platform (Title: Violence in the media).

professions with no connection, e.g., banker). Ratings were either positive (4 or 5 out of 5 stars) or negative ( 1 or 2 out of 5 stars), and the numbers of contributors to the rating were either low ( 2 to 11 raters) or high (101 to 119 raters). The difference in the numbers of raters was supposed to be salient due to the possibility of directly comparing them. For each combination of author information, a fictitious "character" was created (e.g., "Dr. Michael Becker, psychologist, community rating: 2 out of 5 stars, rated by 3 persons").

Furthermore, an additional between-subjects factor with regard to the information about the community of the blog platform was varied: Half of the participants received no further information, while in the other condition, a 
text on the overview page was displayed reporting that only registered users (who have children themselves and have successfully completed a multiplechoice knowledge test on the topic) were able to rate the articles (additionally, this information was also included in the instructions).

The text material of Study 1 and an additional eight texts in the same style were used.

Moderating variables. Besides age and education, the users' need for cognition (Cacioppo and Petty, 1982; Bless et al., 1994) was measured using 16 items (Cronbach's $\alpha=.82, M=58.40 ; S D=7.94$ ).

Dependent measures. Similar to Study 1, we coded which of the texts from which sources were chosen (in which order) and for how long the texts were read. After using the webpage, participants also rated the credibility of the authors using three adjective pairs concerning competence and three concerning trustworthiness (Gierl et al., 1997; Cronbach's $\alpha$ between .74 and .92).

Procedure. First, participants filled out a pre-questionnaire, and were then asked to look at the blog website and to inform themselves about the topic during four minutes of reading time. After this, participants completed the credibility ratings.

\subsection{Results}

Participants selected an average of 5.68 articles $(S D=2.62)$ for further reading. As statistical tests of the hypotheses, ANOVAs with repeated measures were conducted. Self-reported expertise, valence of community ratings, number of community ratings, and author's gender were included as within-subject factors, and the information on the community (none vs. information about reliable members) was entered as between-subject factor.

Results showed significant effects of author expertise, $F(1,38)=34.92$, $p<.001, \eta_{p}{ }^{2}=.48$, valence of community ratings, $F(1,38)=10.80, p=.002$, $\eta_{p}{ }^{2}=.22$, and of gender, $F(1,38)=22.54, p<.001, \eta_{p}{ }^{2}=.37$, on the perceptions of credibility. In other words, authors with a high level of self-reported expertise were evaluated as more credible $(M=21.11$; $S E=0.44)$ than their low-expertise counterparts $(M=17.29 ; S E=0.41)$. Furthermore, participants perceived authors with a positive rating $(M=19.99 ; S E=0.32)$ as more credible (negative: $M=$ 18.42; $S E=0.40)$, and female authors $(M=19.61$; $S E=0.31)$ were evaluated as more credible than males $(M=18.80 ; S E=0.26)$. Moreover, a significant threeway interaction between expertise, gender, and number of ratings emerged, $F$ $(1,38)=9.05, p=.005, \eta_{p}{ }^{2}=.19$, which did not qualify the main effects. The separate analysis for perceived competence yielded a very similar pattern of 
main effects. In the dimension of perceived trustworthiness, however, the effect of author expertise was less pronounced, $F(1,38)=4.49, p=.041, \eta_{p}{ }^{2}=.11$, than the effect of community ratings, $F(1,38)=14.08, p=.001, \eta_{p}{ }^{2}=.27$.

Against expectations, there were no significant main effects of expertise or ratings on the frequency of selection. Instead, a significant effect of authors' gender emerged, $F(1,38)=5.97, p=.019, \eta_{p}{ }^{2}=.14$, indicating that texts which were attached to women $(M=0.40 ; S E=0.03)$ were selected more frequently for further reading than texts of male authors $(M=0.31 ; S E=0.03)$.

For reading time, ANOVA showed significant effects of valence of community ratings, $F(1,38)=4.74, p=.036, \eta_{p}{ }^{2}=.11$, and gender, $F(1,38)=6.08, p=$ $.018, \eta_{p}{ }^{2}=.14$. Articles from sources with a positive rating $(M=9.83 ; S E=0.69)$ were read for longer than their negative-rating counterparts $(M=7.40 ; S E=$ $0.64)$, and participants spent more reading time on articles by female authors $(M=10.08 ; S E=0.74 /$ male: $M=7.16 ; S E=0.64)$.

With regard to the order of selection, results did not show significant effects.

In terms of the effects of reader characteristics and credibility perceptions on the preference for certain sources, we conducted regression analyses for moderation and mediation effects in within-subject designs (Judd et al., 2001). Scores for the individual preference for expert sources and for the preferences for texts with positive ratings were regressed on age, education, need for cognition, and the between-subject factor regarding the information about the community. Furthermore, the perceived credibility differences between experts and layperson authors and between authors with positive and negative ratings were included as potential predictors. For the difference score of expert minus layperson texts, none of the predictors was significant. For the individual preference for authors with positive ratings over authors with negative ratings, the factor of information about the community $(\beta=.306, p=.041)$ and readers' NC ( $\beta=.370, p=.019$ ) emerged as significant predictors: Participants who received the information that the ratings were given by competent community members selected articles from high-rating sources more often, and readers with higher levels of NC paid more attention to the rating information. The perceived credibility difference between positively and negatively rated sources $(\beta=.385, p=$ .015) was a further significant predictor in the regression model $\left(R^{2}=.324\right)$, indicating a mediation effect of credibility perceptions. The number of selected texts by female authors did not differ between female and male participants.

In summary, results showed several effects of source factors when selecting articles on the topic of violence in the media on a blog platform. Most consistently, female authors were regarded as more credible and their texts were selected more often and read for longer (RQ 1). H4 was only supported insofar as 
expert authors were evaluated as more credible. The valence of community ratings significantly affected credibility perceptions and reading time (partially supporting H5); particularly readers with higher need for cognition included this cue in their selection decisions. In line with H6, the preference for texts by authors with a positive rating was particularly relevant when it was mentioned that the ratings were made by a competent community. However, the number of people who contributed to the ratings did not affect the consideration of the ratings.

\section{Discussion}

The diversity of sources on the web has raised questions about how internet users select information and whether they engage in preliminary assessments regarding the credibility of the sources. In this context, the goal of this work was to investigate the effects of source cues and recommendations by other users, both of which can be used to infer the quality of the given content, on readers' selection behavior on a news aggregator website and on a Web 2.0 blog platform.

In Study 1, the experimentally manipulated webpage showed articles from journalistic sources with high and low reputation and displayed ratings by the community and numbers of people who had clicked on the article previously. Results showed that participants generally preferred articles from reputable sources, which were not only perceived as more credible but also selected more frequently, read for longer, and selected earlier - regardless of content, which was kept constant and systematically rotated. This suggests that cues about the reputation of the source are relevant not only when processing information (Hovland et al., 1953; Pornpitakpan, 2004) but also at the earlier stage when deciding which articles to choose for further reading (Sundar et al., 2007): Since credibility can be seen as a central aspect which is necessary to make use of a piece of information (Wathen and Burkell, 2002), it is a reasonable strategy that users engage in credibility assessments by paying attention to the sources. The effects can be explained with the authority heuristic (Metzger et al., 2010; Sundar, 2008) but they may also be based on more systematic assessments or previous experiences with the given sources. According to mediation analyses, differences in credibility perceptions can be described as the underlying explanation of differences in selection behavior.

The community ratings which were displayed below the sources also affected perceptions of credibility, particularly in combination with a high number 
of views since this may suggest that the rating is based on a larger number of 'votes'. However, positively and negatively rated sources did not differ significantly with regard to participants' choices of which articles to read. Sources with a positive rating were only preferred by readers who perceived larger credibility differences between positively and negatively rated sources or selected earlier when the source reputation was low. This suggests that source reputation was the most important cue in this setting and the rating was taken into account when readers had doubts about the reputation (Sundar et al., 2007). Results did not show a bandwagon effect (Chaiken, 1987) in that articles which had been frequently clicked on previously were preferred by the users. One explanation for this might be that both very high numbers (as indicators of popularity) and very low numbers (as indicators of recency) convey positive impressions (Knobloch-Westerwick et al., 2005) - but as there was no further variation of this factor in this setting, this interpretation cannot be tested here. However, it appears that readers' bandwagon perceptions (Sundar, 2008) were less important than the source reputation in the context of a website offering articles from journalistic sources. This result differs from the setting of e-commerce, in which numerous studies have shown effects of product ratings or consumer reviews (e.g., Chevalier and Mayzlin, 2006). One reason for this difference might be that peers who bought a certain product have valuable information which may exceed the credibility of official sources. When selecting articles for further reading, recipients are less dependent on others' experiences since they probably know about the general credibility of famous news sources themselves.

Study 2 tested the effects of source cues and other-generated information in a Web 2.0 environment (in which less is known about the original sources). In this setting, a more complex pattern of results emerged: The level of expertise as a traditional marker of credibility (Hovland et al., 1953), resembling the source reputation of newspapers, was important for the perceptions of credibility (especially with regard to perceived competence and to a lesser extent with regard to perceived trustworthiness [Willemsen et al., 2012]) but not for the selection behavior. While previous studies showed effects of author expertise on information selection (Winter and Krämer, 2012), the design of this blog page may have shifted readers' attention to the ratings: Due to the salience of these evaluations through the indication of how many people contributed to the scores, it is likely that participants perceived the community's information as reliable. Results showed that texts by authors with a positive rating were regarded as more credible and therefore read for longer than texts by authors with a negative rating. The consideration of the rating was particularly high when participants received the information that ratings were made by regis- 
tered members. This indicates that bandwagon information (Sundar, 2008) on blog sites can become the primary cue for information selection if readers perceive the community itself as competent and reliable.

As one personal characteristic of the authors, gender emerged as an important factor for credibility assessments as well as for the selection of information: Results showed that participants selected texts by women more frequently and spent more reading time on them. This result was not affected by participants' gender, suggesting that there was no pattern of social comparison as was previously shown for the selection of news stories with regard to the protagonist's gender (Knobloch-Westerwick and Hastall, 2006). One reason could lie in the topic of the effects of violence in the media on children, in which women may appear more competent due to their presumably greater experience in childrearing. For other topics, effects of gender may be different. On a more general level, the result shows that basic personal information of blog authors is taken into account by the recipients.

When comparing the effects of source cues and more web-specific bandwagon cues in the two different settings ("Web 1.0" vs. Web 2.0), it appears that the traditional source factor of reputation is more relevant in the context of news aggregators, while the importance of community ratings increases in the context of user-generated content. Since readers mostly do have knowledge about, or experience with, certain news sources but not with specific bloggers, ratings by others can be more valuable in a blog setting. However, the effects of the ratings are more complex and seem to depend on whether readers trust the members of the community.

As a limitation of the present studies, it should be mentioned that the amount of information presented in the experiments is smaller than the variety that can be found online. Furthermore, the neutral texts and the design of the experimental webpages might have appeared artificial. However, we tried to design the stimulus material similar to existing websites. The heterogeneous sample with parents can be seen as advantageous compared to student samples, as the results may have more external validity with a group that is interested in the topic. In comparison to earlier studies on selective exposure, the selection behavior was not assessed via questionnaire but with screen recordings of the actual usage. For future research, eye-tracking studies could provide even more fine-grained data about readers' assessments of cues.

In summary, the findings extend research on selective exposure by showing that readers engage in preliminary assessments of credibility when deciding which articles to read online. Therefore, credibility cues can be regarded as a further factor influencing the selection of information besides attitude consistency (Knobloch-Westerwick and Meng, 2009), topical relevance, or utility of 
information (Pirolli and Card, 1999). When selecting journalistic stories, readers focus on the traditional cue of source reputation. When selecting user-generated content, readers include evaluations by others in their decisions if the community of the website appears to be competent, although more work is needed to clarify these attributions. Future research could investigate the effects of authority and bandwagon cues in other contexts and potential interactions of these factors with different message types and levels of motivation. Addressing these questions may help to shed light on the increasingly important question of how internet users cope with the ever-growing amount of information online and the diversity of sources.

Acknowledgments: The present research was funded by the Deutsche Forschungsgemeinschaft (DFG, German Research Foundation) in the Special Priority Program "Science and the General Public" (Kr 2240/2). The authors would like to thank Kathrin Schielke, Leonie Rösner, German Neubaum, and Jana Appel for their help collecting data.

\section{References}

Bless, H., Wänke, M., Bohner, G., Fellhauer, R. F., \& Schwarz, N. 1994. Need for Cognition: Eine Skala zur Erfassung von Engagement und Freude bei Denkaufgaben [Need for cognition: A scale for the assessment of involvement and enjoyment of cognitive tasks]. Zeitschrift für Sozialpsychologie, 25, 147-154.

Bromme, R., Kienhues, D., \& Porsch, T. 2010. Who knows what and who can we believe? Epistemological beliefs are beliefs about knowledge (mostly) attained from others. In L. D. Bendixen \& F. C. Feucht (Eds.), Personal epistemology in the classroom: Theory, research, and implications for practice (pp. 163-193). Cambridge, England: Cambridge University Press.

Cacioppo, J. T., \& Petty, R. E. 1982. The need for cognition. Journal of Personality and Social Psychology, 42(1), 116-131.

Chaiken, S. 1987. The heuristic model of persuasion. In M. Zanna, J. Olson \& C. Herman (Eds.), Social influence: The Ontario Symposium (Vol. 5, pp. 3-39). Hillsdale, N): Lawrence Erlbaum Associates.

Chevalier, J. A., \& Mayzlin, D. 2006. The effect of word of mouth on sales: Online book reviews. Journal of Marketing Research, 43(3), 345-354.

Donsbach, W. 1991. Exposure to political content in newspapers: The impact of cognitive dissonance on readers' selectivity. European Journal of Communication, 6(2), 155-186.

Eveland, W. P., Jr. \& Dunwoody, S. 2002. An investigation of elaboration and selective scanning as mediators of learning from the web versus print. Journal of Broadcasting \& Electronic Media, 46(1), 34-53.

Flanagin, A. J., \& Metzger, M. J. 2003. The perceived credibility of personal web page information as influenced by the sex of the source. Computers in Human Behavior, 19(6), 683-702. 
Gierl, H., Stich, A., \& Strohmayr, M. 1997. Einfluss der Glaubwürdigkeit einer Informationsquelle auf die Glaubwürdigkeit der Information [The influence of source credibility on information credibility]. Marketing Zeitschrift für Forschung und Praxis, 19, 27-31.

Hovland, C. I., Janis, I. L., \& Kelley, H. H. 1953. Communications and persuasion: Psychological studies in opinion change. New Haven, CT: Yale University Press.

Judd, C. M., Kenny, D. A., \& McClelland, G. H. 2001. Estimating and testing mediation and moderation in within-participant designs. Psychological Methods, 6, 115-134.

Kang, H., Bae, K., Zhang, S., \& Sundar, S. S. 2011. Source cues in online news: Is the proximate source more powerful than distal sources? Journalism \& Mass Communication Quarterly, 88(4), 719-736.

Knobloch-Westerwick, S., \& Hastall, M. R. 2006. Social comparisons with news personae: Selective exposure to news portrayals of same-sex and same-age characters. Communication Research, 33(4), 262-284.

Knobloch-Westerwick, S., \& Meng, J. 2009. Looking the other way: Selective exposure to attitude-consistent and counter-attitudinal political information. Communication Research, 36(3), 426-448.

Knobloch-Westerwick, S., Sharma, N., Hansen, D. L., \& Alter, S. 2005. Impact of popularity indications on readers' selective exposure to online news. Journal of Broadcasting \& Electronic Media, 49(3), 296-313.

Lee, E.-J., \& Jang, Y. J. 2010. What do others' reactions to news on internet portal sites tell us? Effects of presentation format and readers' need for cognition on reality perception. Communication Research, 37(6), 825-846.

Metzger, M. J., Flanagin, A. J., Eyal, K., Lemus, D. R., \& McCann, R. 2003. Credibility in the $21^{\text {st }}$ century: Integrating perspectives on source, message, and media credibility in the contemporary media environment. In P. Kalbfleisch (Ed.), Communication Yearbook 27 (pp. 293-335). Mahwah, N): Lawrence Erlbaum.

Metzger, M. J., Flanagin, A., \& Medders, R. 2010. Social and heuristic approaches to credibility evaluation online. Journal of Communication, 60(3), 413-439.

Pirolli, P., \& Card, S. K. 1999. Information foraging. Psychological Review, 106(4), 643-675.

Pornpitakpan, C. 2004. The persuasiveness of source credibility: A critical review of five decades' evidence. Journal of Applied Social Psychology, 34(2), 243-281.

Sundar, S. S. 2008. The MAIN model: A heuristic approach to understanding technology effects on credibility. In M. J. Metzger \& A. J. Flanagin (Eds.), Digital media, youth, and credibility (pp. 72-100). Cambridge, MA: The MIT Press.

Sundar, S. S., Knobloch-Westerwick, S., \& Hastall, M. 2007. News cues: Do indicators of newsworthiness by newsbots affect our perception of news stories? A cross-cultural study in Germany, the Netherlands, and the U.S. Journal of the American Society of Information Science and Technology, 58(3), 366-378.

Sundar, S. S., \& Nass, C. 2001. Conceptualizing sources in online news. Journal of Communication, 51(1), 52-72.

Tseng, S., \& Fogg, B. J. 1999. Credibility and computing technology. Communications of the $A C M, 42(5), 39-44$.

Wathen, C. N., \& Burkell, J. 2002. Believe it or not: Factors influencing credibility on the web. Journal of the American Society for Information Science and Technology, 53(2), 134-144. 
Westerwick, A., Kleinman, S. B., \& Knobloch-Westerwick, S. 2013. Turn a blind eye if you care: Impacts of attitude consistency, importance, and credibility on seeking of political information and implications for attitudes. Journal of Communication, 63(3), 432-453.

Willemsen, L. M., Neijens, P. C., \& Bronner, F. 2012. The ironic effect of source identification on the perceived credibility of online product reviewers. Journal of Computer-Mediated Communication, 18(1), 16-31.

Winter, S., \& Krämer, N. C. 2012. Selecting science information in web 2.0: How source cues, message sidedness, and need for cognition influence users' exposure to blog posts. Journal of Computer-Mediated Communication, 18(1), 80-96.

Winter, S., Krämer, N. C., Appel, J., \& Schielke, K. 2010. Information selection in the blogosphere - The effect of expertise, community rating, and age. In S. Ohlsson \& R. Catrambone (Eds.), Proceedings of the $32^{\text {nd }}$ Annual Conference of the Cognitive Science Society (pp. 802-807). Austin, TX: Cognitive Science Society. 


\section{DuEPublico}

\section{Duisburg-Essen Publications online}

offen im Denken

$\mathbf{U b} \mid \begin{gathered}\text { universitäts } \\ \text { bibliothek }\end{gathered}$

This text is made available via DuEPublico, the institutional repository of the University of Duisburg-Essen. This version may eventually differ from another version distributed by a commercial publisher.

DOI: $\quad 10.1515 /$ commun-2014-0020

URN: urn:nbn:de:hbz:464-20200529-101101-4

All rights reserved.

This publication is with permission of the rights owner freely accessible due to an Alliance licence and a national licence (funded by the DFG, German Research Foundation) respectively. 